\title{
Abnormal Returns and Stock Splits: The Decimalized vs. Fractional System of Stock Price Quotes
}

\author{
Carroll Howard Griffin, Ph.D. \\ Eckelkamp College of Global Business and Professional Studies \\ Fontbonne University \\ 6800 Wydown Blvd. St. Louis MO 63105, USA
}

Tel: 1-210-569-9967Ｅ-mail: chgriffin@hotmail.com

The author will also serve as the corresponding author and will handle all correspondence.

\begin{abstract}
Stock splits have been an anomaly in the world of finance since their inception. Despite the fact that stock splits themselves do not inherently create any value for the firm, investors see stock splits as positive and the companies that declare them as better investments than ones that do not. With the inception several years ago of the decimalized system of stock price quotations, it remains to be seen if stock splits will continue to be seen as such, and if so, to a greater or lesser degree as under the fractional quote system. It seems that despite a reduction in transaction costs under the new system, there again appears to be no long-term benefit to splitting.
\end{abstract}

Keywords: Portfolio choice, Investment decisions, Stocks, Stock splits, Abnormal returns

\section{Introduction}

Since their inception, stock splits have been somewhat of an anomaly in the world of finance. They do not create value in and of themselves; they merely "slice the pie" into smaller and smaller pieces. They are merely a capital structure alteration which, in perfect market conditions, should have no effect on firm value (Muscarella and Vetsuypens, 1994). In other words, if a company's stock is trading at $\$ 100$ per share, if it were to declare a 2 -for-1 stock split, an investor who formerly held 1 share at $\$ 100 /$ share would now hold 2 shares at $\$ 50 /$ share. Thus, on paper, no gain is realized from this action since the stock split simply results in a reduction of the par value and a proportionate increase in the number of shares. However, for several reasons (some purely psychological, some with a basis in financial theory), which will be dealt with in the following section, many times stock splits are seen as positive and companies that have had a record of consistent stock splits are traded at a premium versus those that have not.

This paper investigates whether or not the change in pricing regime (from fractional to decimalized) has had an effect on the abnormal return experienced through the splitting of a company's stock. The study is structured as follows- a literature review related to stock splits and the decimalized vs. fractional system of stock prices, methodology and data, results, interpretations and conclusions.

\section{Stock Split Theories}

Traditional wisdom in corporate finance circles indicates that stock splits are a positive occurrence and that they are indicative of a company's positive future performance. However, it is unclear why this would be the case, as there is no upper level boundary on a stock's price as well as the existence of other positive indicators portending strong future performance, such as increased dividends per share. According to Ikenberry, "A split is one of the emptiest things; companies don't produce more widgets because of them." (Ryser, 1996) Furthermore, empirical research has documented several negative consequences of stock splits, such as increased volatility, larger spreads and increased transaction costs following a stock split (Easley et al, 2005).

Despite this empirical mystery, many financial economists nonetheless feel that the splitting of stock produces a greater total market value for the shares outstanding (Lyroudi et al, 2006). There are several theories which have attempted to explain why, despite creating no value on paper, stock splits tend to be viewed as positive by investors. The widespread view is that it is attributable to psychological reasons to a large degree (versus economic reasons alone). The most prominent, dating back to Fama et al (1969), are the Positive Signaling Hypothesis and the Optimal Trading Range Hypothesis, along with several others. 


\subsection{Positive Signaling Hypothesis}

The Positive Signaling Hypothesis states that investors tend to view a stock split as a positive signal for a firm's future prospects and will tend to purchase these shares, thus creating a rise in stock price. Brennen and Copeland (1988) and McNichols and Dravid (1981) interpreted the positive stock market reaction to split announcements as an indication of company executives' possession of positive insider information. In an empirical study by Elfakhani and Lung, the authors demonstrate that company executives may use stock splits to signal private information to investors regarding a positive change in the firm's value. The rationale is that executives will only proceed with a stock split if they believe that the firm will do well in the future. If average or poor prospects for the future are believed to be had, company executives will not incur the administration expense of a stock split and have the stock price decline, much less decline below what is considered the "optimal trading range" (2003). Therefore, investors view stock splits as a tool that can reduce informational asymmetries (Easley et al, 2005).

According to Lyroudi et al, each stock split gives different signals from the executives to the investors. Regardless of the firm's conditions and purposes, there is a positive market reaction to the announcement of a split (2006). However, managers tend to base their decision to split a stock on strong past performance rather than the belief that future performance will be exceptional (Kadiyala and Vetsuypens, 2002).

According to signaling theory, for the content of the signal to be credible, there must be a penalty associated with sending a false signal (Crawford and Franz, 2001). Supporting this view, previous "false signalers" tend to experience a less positive market response the next time a stock split is declared (Doran, 1995). Also, the market tends to use previous split experience to interpret the current stock split, and then that post-split stock price response depends on earnings realizations after previous splits (Pilotte and Manuel, 1996). Pessimistic managers are less likely to undertake a stock split, fearing that the post-split stock price may fall below an acceptable level. Thus, there may be a self-selection bias present in the sense that only managers optimistic about their company's future performance will choose to split the stock (Ikenberry et al, 1996).

One basic reason for exercising a stock split is simply to conform to the market norm, which is established by mutual reinforcement among the financial community. Few firms deviate from this by not splitting when the prices have increased substantially. This implies that models based on economic reasons alone do not fully describe the rationality of stock splits--there is some other factor at work (So and Tse, 2000).

\subsection{Optimal Trading Range Hypothesis}

The second theory is the Optimal Trading Range Hypothesis. This states that investors, either consciously or subconsciously, seek out stocks that trade within a certain range, usually between $\$ 30$ and $\$ 60$. If a stock passes the upper limit of this range, many times the company in question will declare a stock split to once again bring down the share price to the "optimal" range. This optimal trading range is largely psychological, as investors with a limited amount of investment funds would prefer to receive more stock shares than fewer, even though the amount invested would be the same.

The idea of an optimal trading range is widely supported by practitioners, who generally state that a lower share price makes it easier for smaller investors to hold shares (So and Tse, 2000). According to Teweles and Bradley (1987), the increase in "round lot" (purchase orders in units of 100 shares), facilitated by stock splits is used to increase a firm's shareholder base and thereby improves its liquidity. According to Amihud and Mendelson (1986), there is a positive relationship between equity value and liquidity. According to these authors, rational investors discount illiquid shares more heavily than liquid shares because of the higher transaction costs that are incurred with the former. In an empirical study by Elfakhani and Lung, they show that following the split event, the trading volume and number of transactions increase, suggesting that split events enhance liquidity. However, this relates stock splits more to past performance than to future performance (2003). As stated above, only optimistic managers will choose to undertake a stock split for fear that the post-split stock price perhaps may fall below the optimal range of trading.

\subsection{Other Hypotheses}

Under the Neglected Firm Hypothesis, Arbel and Swanson (1993) state that if there is little known information about a firm, its shares will trade at a discount. Therefore, many times the firm's managers use the stock split to attract attention to the stock in question. Also, the Liquidity Hypothesis states that the splitting of stock increases its market liquidity and will thus attract more small investors. (Crawford et al, 2005). Lastly, the Retained Earnings Hypothesis states that since a stock split reduces retained earnings per share, managers are seen as being confident that they will be able to replenish retained earnings per share in the future with increased earnings (Lyroudi et al, 2006). 


\section{Stock Splits and Decimalization}

In March 1997, Congressman Michael Oxley (R-OH) introduced a bill directing the Securities and Exchange Commission to adopt a dollars and cents (i.e. decimalized) system of stock trading (Bollen and Busse, 2006). The bill was approved; then beginning in 1998, stocks began to make the transition from the $1 / 8$ pricing scheme when the minimum fraction became 1/16. In 2001, decimalization came into full effect on the NYSE and NASDAQ. This reduced the "tick size" (the minimum amount of change in a stock price) from 1/8 to $1 / 16$ of a dollar to $\$ .01$. One of the important results of this was a more narrow bid-ask spread and price discreteness (Kadapakkam et al, 2005). Studies have shown that tick size had often been a binding constraint on spreads, and a reduction in tick size benefits small investors (Bollen and Busse, 2006). In fact, discreteness in price changes, as under the fractional system (versus a continuous change under decimalization) has long been recognized as a problem in examining stock price behavior (Bali and Hite, 1998).

Before the decimalization of stock prices, the tick played a liquidity role by providing brokers more incentive to become active in the sale of split shares due to an increase in profit from the minimum bid-ask spread for each share. Although some argued that this was liquidity enhancing, in general it was agreed that it slowed the dollar volume of trading by making the cost of trading higher for the average (i.e. small) investor (Ryser, 1996). Before decimalization, stock splits were costly because the fixed cost element of brokerage commissions increased the per-share trading costs of lower priced stocks (Ikenberry et al, 1996).

According to the Broker Promotion Hypothesis, the increase in relative spread after a stock split encourages brokers to promote splitting stocks to their small investors. During the $1 / 8$ pricing period, after the split date, the relative spread increased significantly. After decimalization, these changes have been smaller. In a preliminary study, it was found that there were significant positive abnormal returns around the split date during the 1/8 pricing period but not in the decimal pricing period. Thus, decimalization has decreased bid-ask spreads; therefore, it has reduced the incentives for brokers to promote a stock after it splits (Kadapakkam et al, 2005). Confirming these results, Chou et al (2005) found that the abnormal post-split day returns have decreased, and the abnormal trading volume has increased in the decimal pricing era versus the 1/8 pricing era. According to $\mathrm{He}$ and $\mathrm{Wu}(2005)$, the move to decimalization caused a decrease in rounding errors and serial correlation of price changes. Lastly, Hardin et al (2007) found that discreteness and other transaction costs are reduced with decimalization.

However, one of the major obstacles when examining the effect of stock splits and price reactions is the fact that many times these announcements are made in conjunction with other corporate announcements; therefore, it leads to the challenge of how to disentangle the effects (Liljeblom, 1989). Also, there is evidence indicating that stock prices, even several years after the full implementation of decimalization, tend to cluster at the 5 and 10 cent increment levels. For many stocks, these two increments comprise more than half of all closing prices. This extensive degree of price clustering tends to point to a psychological bias toward round numbers. Therefore, as stated by the SEC, full decimalization may not be necessary and other tick sizes may be considered in the future (Ikenberry and Weston, 2003).

\section{Methodology and Data}

Again, this paper investigates whether or not the change in pricing regime (from fractional to decimalized) has had an effect on the abnormal return experienced through the splitting of a company's stock. An event study methodology with 80 observations (i.e. companies) will be used, with several trading windows from 10 days to 250 days post-split (i.e. up to one full year of post-split trading.) All trading windows will begin 10 days before the split in order to determine if there are any abnormal returns stemming from the mere expectation of the split and what it could signal for the firm. CRSP daily stock return data will be used to analyze abnormal returns with data observations taken from the list of 2007 Fortune 500 companies. To qualify as an observation, the company had to have declared a stock split under the 1/8 dollar fractional system (up to 1998) as well as under the decimalized system (between 2001 and 2005, in order to obtain a full year of post-split trading data). All returns will be Cumulative Adjusted Returns (Market Adjusted). The objective will be to investigate if the presence of long-term price effects of stock splits has been more persistent and/or positive under the $1 / 8$ dollar (i.e. fractional) system or decimalization system.

\section{Results}

Results from the event study are the following:

\subsection{Fractional System}

As can be seen, under the fractional system, there was a slightly positive CAR upon the splitting of the stock but 
it becomes increasingly negative over time in the year after the split. This perhaps could be attributed to the greater spreads (as a percent of share price) charged by brokers under the fractional system post-split (and thus greater transaction costs for investors looking to buy or sell these stocks), along with increased levels of volatility, etc.

\section{Table 1 Here}

\section{Table 2 Here}

As can be seen from the above sample of the largest (as measured by revenues) companies, the mean CAR behaves in much the same way as does the entire sample under the fractional system, but has less negative CARs over the time periods in question.

\section{Table 3 Here}

\section{Table 4 Here}

As can be seen from the above medium and small company samples, the mean CARs behave in much the same way as the entire sample, only are much more negative over the time periods in question and much more than the large company sample.

\subsection{Decimalized System}

The following graphs illustrate the cumulative abnormal returns under the decimalized system.

\section{Table 5 Here}

Under the decimalized system, there is a positive CAR in the days leading up to the split and extending out to 90 days after the split, diminishing over time. However, the occurrence day CAR is essentially zero, confirming that the Broker Promotion Hypothesis effect has decreased since the implementation of the decimalized system. However, the CAR diminishes and eventually becomes negative as time progresses (although it is much less so than under the fractional system). This perhaps could indicate that there is indeed no value created by the stock split and event factors (i.e. transaction costs, increased volatility, etc.) cause there to be a slightly negative effect brought on by stock splits.

\section{Table 6 Here}

\section{Table 7 Here}

\section{Table 8 Here}

Under the decimalized system, the CARs seem to vary a great deal based on size of the firm, with the effects accentuated as time progresses. As can be seen, the small company sample experienced highly positive CARs over the period in question. This perhaps could be due to the fact that the market usually has less other information to base decisions on for the smaller firms, thus placing more value on the stock split announcement than for the large and medium firm samples.

\subsection{Stock Splits and the Price of the Stock upon Split}

In this section the Optimal Trading Range Hypothesis will be examined to determine if there is more or less abnormal return depending upon at what price the stock split and whether or not the change in stock price quotations has any influence on this. Graph 9 below presents overall results for stocks splitting at $\$ 60$ or above.

\section{Table 9 Here}

\section{Table 10 Here}

As the above samples show, when a stock splits when the price is at least $\$ 60$, there is a large abnormal return up to 90 days after the split. Additionally, as graph 10 depicts, there is very little abnormal return at any point when the stock splits at below $\$ 60$. This is further confirmed by graph 11 . When a stock split at under $\$ 60$ a share under the previous fractional system, negative CARs were experienced throughout the entire time frame, with the exception of a slightly positive CAR on the announcement date (note- there were no samples for splitting at over $\$ 60$ per share for the fractional system).

\section{Table 11 Here}

Table 12 Here

\section{Table 13 Here}

However, under the new decimalized system, the results are not quite as clear cut. Stocks splitting at above $\$ 60 /$ share under the current pricing regime tend to experience positive CARs out to 90 days, but again, tend to 
revert negatively after that point. Stocks splitting at under $\$ 60 /$ share also experience positive CARs around the announcement time and thereafter, with only a slight negative tendency.

Taken together, these graphs would tend to support the Optimal Trading Range Hypothesis in the sense that investors would rather buy a stock that is in the $\$ 30-\$ 60$ range and consider the splitting of a stock at $\$ 60$ or above a positive event. In almost all samples, however, past 90 days the CAR reverts back to the pattern that we have seen thus far- negative CARs after a certain time frame. This also lends support to the conclusion that stock splits truly do not add any value in and of themselves; however, they are seen as a positive occurrence by practitioners and create a sort of short-term self-fulfilling prophecy.

\subsection{The Size of the Split and the Amount of Abnormal Return}

In this section the size of the stock split will be examined to determine if the fractional split size has any impact on the amount of abnormal return. According to the Signaling Hypothesis, a stock split portends a positive trend in the stock price. In this section, the three most common split fractions (2-for-1, 3-for-2 and 3-for-1) will be examined.

In Graph 14 below, the entire sample of companies (under both the fractional and decimalized systems) which have split on a 2-for-1, 3-for-2 and 3-for-1 basis is examined. As can be seen under the 2-for-1 split sample, the CAR remains positive throughout the pre-announcement period and up to 90 days after the announcement. However, consistent with previous tests, the CAR begins to turn negative at some point (in this case beginning at 180 days), thus confirming that a stock split has indeed only a temporary effect. Stocks that have split 3-for-2 have appeared to provide less cumulative abnormal return over most of the period in question. The positive CAR over the last part of the period is unexplainable and may be due to other factors. For the 3-for-1 sample, the CAR is extremely negative during all of the post-announcement phase (and increasingly so over time). Perhaps although a 3 -for-1 split is initially seen as a positive event, very few companies have enough earnings to sustain adequate earnings per share after such a split.

\section{Table 14 Here}

\section{Table 15 Here}

Table 16 Here

\section{Table 17 Here}

Table 18 Here

As the above graphs demonstrate, under the 2-for-1 split ratio, there was more positive abnormal return under the decimalized system than under the fractional system (although many returns were still negative post-split). Additionally, large companies fared slightly better splitting under this ratio in the current decimalized system. The 3-for-1 ratio was not tested further due to extremely negative preliminary tests and the lack of stocks splitting under this ratio. Under the 3- for-2 split ratio, the sample stocks categorized as small experienced positive cumulative abnormal returns in many cases under the fractional system as well as under the current decimalized system. Abnormal returns under this ratio seemed much greater than under the 2 -for- 1 ratio (under both systems) for smaller companies. This seems to indicate that the 3-for-2 ratio for small and medium sized companies is the optimal ratio for stock splits while the 2-for-1 ratio appears to be more advantageous for large companies under the current stock price system.

\section{Interpretation of Results}

In general terms, there has been less negative/more positive Cumulative Abnormal Return under the decimalized system than under the fractional system. However, despite a reduction in transaction costs under the new system, there appears to be no long-term benefit to splitting. Under the fractional system, there is the presence of abnormal returns during the announcement period (thus confirming the idea that investors and practitioners tend to see splits as positive events), but fairly significant negative Cumulative Abnormal Returns post-split. Under the decimalized system, positive CARs also exist in the time leading up to and upon the split, with much less severe (although still slightly negative) abnormal returns post-split. These results tend to confirm the idea that although investors see stock splits as a positive event (possibly due to the Signaling Hypothesis), as do many company managers and other practitioners, in reality they create no value for the firm. In addition, due to transaction costs, possible increased volatility and other unknown factors, there is the likelihood of negative returns in the year following the split.

Regarding the size of split, the results seem fairly clear. There does appear to be an optimal split size, but this split size depends in part upon the size of the company and has varied depending on the pricing regime in place 
at the time. Under the old fractional system, a 2-for-1 split was more advantageous for large and medium sized companies while a 3 -for- 2 ratio seemed to work best for smaller companies. However, under the current stock price system, the 3-for-2 ratio has shown to be the optimal split ratio for small and medium sized companies while the 2-for-1 ratio appears to be more advantageous for large companies.

\section{Conclusion}

Stock splits have for many years been considered by practitioners to be a positive event. This has traditionally been explained by primarily two theories--the Positive Signaling Hypothesis and the Optimal Trading Range Hypothesis. According to the Positive Signaling Hypothesis, investors have normally seen stock splits as being a sign by company insiders of good things to come. Company executives foresee the stock price continuing to rise in the near future and feel the stock should be split. This leads to the second major theory of why stocks split, the Optimal Trading Range Hypothesis. This states that psychologically, investors feel more comfortable buying a stock that is trading within a certain range. If it gets beyond this range, investors feel it is too "expensive." Therefore, in order to keep the stock price within that comfortable investor range, company managers will split the stock, thereby reducing the stock price by that amount.

Under the fractional system, the transaction costs after a stock split became greater as a percentage of the stock price. According to the Broker Promotion Hypothesis, brokers would actively promote splitting stocks to the average investor due to the increase in bid-ask spread. However, under the decimalization system, the bid-ask spread adjusts in exact proportion to the reduction in stock price, thus eliminating any undue transaction costs as well as any undue incentive for the broker to recommend the stock to clients. The results of this study tend to confirm this- under the decimalized system, abnormal returns tend to hover closer to zero throughout the period in question, while under the fractional system as a whole, abnormal returns tended to be more positive in the period around the announcement, but then diminished substantially over the rest of the study period. Additionally, there does appear to be an optimal stock split size depending on the pricing regime in place at the time and the size of the company.

\section{References}

Amihoud, Y., \& Mendelson, H. (1986). Liquidity and stock returns. Financial Analyst Journal, 42(3), 43-48.

Arbel, A., \& Swanson, G. (1993). The role of information in stock split announcement effects. Quarterly Journal of Business and Economics, 32(2), 30-50.

Bali, R., \& Hite, G. (1998). Ex-dividend day stock price behavior: discreteness or tax-induced clienteles? Journal of Financial Economics, 47, 127-159.

Bollen, N., \& Busse, J. (2006). Tick size and institutional trading costs: evidence from mutual funds. Journal of Financial and Quantitative Analysis, 41(4), 915-930.

Brennen, M. J., \& Copeland, T.E. (1988). Stock splits, stock prices and transaction costs. Journal of Financial Economics, 22, 83-101.

Chou, R., Lee, W., \& Chen, S. (2005). The market reaction around ex-dates of stock splits before and after decimalization. Review of Pacific Basin Financial Markets and Policies, 8(2), 201-215.

Crawford, D., \& Franz, D. (2001). Stock dividends and splits: anticipation, signaling, and market response. Journal of Accounting, Auditing and Finance, 16(2), 141-157.

Crawford, D., Franz, D., \& Lobo, G. (2005). Signaling managerial optimism through stock dividends and stock splits: a re-examination of the Retained Earnings Hypothesis. Journal of Financial and Quantitative Analysis, 40(3), 531-550.

Doran, D. (1995). Stock splits and false signaling cost within a management reputation framework. Journal of Applied Business Research, 11(3), 115-134.

Easley, D., O'Hara, M., \& Saar, G. (2001). How stock splits affect trading: a microstructure approach. Journal of Financial and Quantitative Analysis, 36(1), 25-48.

Elfakhani, S., \& Lung, T. (2003). The effect of split announcements on Canadian stocks. Global Finance Journal, 14(1), 197-216.

Fama, E., Fisher, L., Jensen, M., \& Roll, R. (1969). The adjustment of stock prices to new information. International Economic Review, 10(1), 1-21.

Hardin, W., Liano, K., Huang, G., \& Nagel, G. (2007). REITs, decimalization, and ex-dividend stock prices. Journal of Real Estate Finance and Economics, 34(4), 499-518. 
He, Y., \& Wu, C. (2005). The effects of decimalization on return volatility components, serial correlation, and trading costs. The Journal of Financial Research, 28(1), 77-95.

Ikenberry, D., \& Weston, J. (2003). Clustering in U.S. stock prices after decimalization. Unpublished manuscript.

Ikenberry, D., Rankine, G., \& Stice, E. (1996). What do stock splits really signal? Journal of Financial and Quantitative Analysis, 31(3), 357-374.

Kadapakkam, P., Krishnamurthy, S., \& Tse, Y. (2005). Stock splits, broker promotion, and decimalization. Journal of Financial and Quantitative Analysis, 40(4), 873-895.

Liljeblom, E. (1989). The informational impact of announcements of stock dividends and stock splits. Journal of Business Finance and Accounting, 16(5), 681-697.

Lyroudi, K., Dasilas, A., \& Varnas, A. (2006). The valuation effects of stock splits in NASDAQ. Managerial Finance, 32(5), 401-419.

McNichols, M., \& Dravid, A. (1981). Stock dividends, stock splits and signaling. Journal of Finance, 42, 857-879.

Muscarella, C., \& Vetsuypens, M. (1994). Stock splits: signaling or liquidity? The case of ADR 'solo-splits'. Working Paper Series.

Pilotte, E., \& Manuel, T. (1996). The market's response to recurring events: the case of stock splits. Journal of Financial Economics, 41, 111-127.

Ryser, J. (1996). Split opinions. CFO, 12(9), 82-97.

So, R., \& Tse, Y. (2000). Rationality of stock splits: the Target-Price Habit Hypothesis. Review of Quantitative Finance and Accounting, 14, 67-84.

Table 1. Entire Sample

$*=$ significant at the .10 level

\begin{tabular}{l|l|l}
\hline Days & Mean CAR (\%) & Generalized Sign Z \\
\hline$(-10,-2)$ & -0.14 & 0.771 \\
$(-1,0)$ & 0.73 & $1.451^{*}$ \\
$(+1,+30)$ & -1.25 & -.362 \\
$(+1,+90)$ & -1.71 & -1.042 \\
$(+1,+180)$ & -3.62 & -0.589 \\
$(+1,+250)$ & -7.04 & -1.042 \\
\hline
\end{tabular}

Table 2. Large Company Sample

Table 3. Medium Company Sample

\begin{tabular}{l|l|l}
\hline Days & Mean CAR (\%) & Generalized Sign Z \\
\hline$(-10,-2)$ & 0.09 & 0.571 \\
$(-1,0)$ & 0.94 & 0.571 \\
$(+1,+30)$ & -0.52 & -0.214 \\
$(+1,+90)$ & 0.49 & 0.179 \\
$(+1,+180)$ & -2.16 & -0.999 \\
$(+1,+250)$ & -1.17 & 0.571 \\
\hline
\end{tabular}

\begin{tabular}{l|l|l}
\hline Days & Mean CAR (\%) & Generalized Sign Z \\
\hline$(-10,-2)$ & -1.03 & -.453 \\
$(-1,0)$ & 0.34 & 0.748 \\
$(+1,+30)$ & -0.93 & -0.853 \\
$(+1,+90)$ & -4.23 & -0.853 \\
$(+1,180)$ & -6.01 & -0.053 \\
$(+1,+250)$ & -10.01 & -1.253 \\
\hline
\end{tabular}


Table 4. Small Company Sample

$* *=$ significant at the .05 level

\begin{tabular}{l|l|ll}
\hline Days & Mean CAR (\%) & Generalized & Sign Z \\
\hline$(-10,-2)$ & 0.18 & 0.749 & \\
$(-1,0)$ & 0.50 & 1.070 & \\
$(+1,+30)$ & -2.32 & -0.854 & \\
$(+1,+90)$ & -3.02 & $-1.815^{* *}$ & \\
$(+1,180)$ & -4.19 & -0.212 & \\
$(+1,+250)$ & -10.76 & $-1.495^{*}$ & \\
\hline
\end{tabular}

$*$ significant at the .10 level

Table 5. Entire Sample

$* *=$ significant at the .05 level

\begin{tabular}{l|l|l}
\hline Days & Mean CAR (\%) & Generalized Sign Z \\
\hline$(-10,-2)$ & 1.84 & $2.309^{* *}$ \\
$(-1,0)$ & -0.09 & 0.497 \\
$(+1,+30)$ & 1.36 & 0.950 \\
$(+1,+90)$ & 1.41 & 0.950 \\
$(+1,+180)$ & 0.79 & 0.044 \\
$(+1,+250)$ & -0.10 & -0.635 \\
\hline
\end{tabular}

Table 6. Large Company Sample

$*$ = significant at the .10 level

\begin{tabular}{l|l|l}
\hline Days & Mean CAR (\%) & Generalized Sign Z \\
\hline$(-10,-2)$ & 1.88 & $2.006^{* *}$ \\
$(-1,0)$ & 0.02 & $1.614^{*}$ \\
$(+1,30)$ & -0.43 & -0.348 \\
$(+1,90)$ & -0.47 & -0.740 \\
$(+1,180)$ & -1.22 & -1.132 \\
$(+1,+250)$ & -1.87 & -0.348 \\
\hline
\end{tabular}

** = significant at the .05 level

Table 7. Medium Company Sample

\begin{tabular}{l|l|l}
\hline Days & Mean CAR (\%) & Generalized Sign Z \\
\hline$(-10,-2)$ & 1.16 & 0.595 \\
$(-1,0)$ & 0.38 & 0.595 \\
$(+1,30)$ & 0.97 & 0.210 \\
$(+1,90)$ & -0.23 & 0.595 \\
$(+1,180)$ & -4.93 & 0.210 \\
$(+1,+250)$ & -6.47 & $-1.330^{*}$ \\
\hline
\end{tabular}

* = significant at the .10 level

Table 8. Small Company Sample

$*=$ significant at the .10 level

\begin{tabular}{l|l|l}
\hline Days & Mean CAR (\%) & Generalized Sign Z \\
\hline$(-10,-2)$ & 2.53 & $-1.415^{*}$ \\
$(-1,0)$ & -0.71 & $-1.385^{*}$ \\
$(+1,+30)$ & 3.65 & $1.815^{* *}$ \\
$(+1,+90)$ & 5.14 & $1.815^{* *}$ \\
$(+1,180)$ & 4.12 & 1.015 \\
$(+1,+250)$ & 8.90 & 0.615 \\
\hline
\end{tabular}

$* *$ significant at the .05 level 
Table 9. “\$60 or Over When Splitting” Company Sample- Overall

$*$ = significant at the .10 level

\begin{tabular}{l|l|l}
\hline Days & Mean CAR (\%) & Generalized Sign Z \\
\hline$(-10,-2)$ & 1.25 & $1.509^{*}$ \\
$(-1,0)$ & -.33 & .906 \\
$(+1,+30)$ & 1.08 & .303 \\
$(+1,+90)$ & 3.53 & .906 \\
$(+1,180)$ & -.71 & -.300 \\
$(+1,+250)$ & -2.07 & .300 \\
\hline
\end{tabular}

Table 10. "Under \$60 When Splitting” Company Sample- Overall

\begin{tabular}{l|l|l}
\hline Days & Mean CAR (\%) & Generalized Sign Z \\
\hline$(-10,-2)$ & 0.87 & $1.963^{* *}$ \\
$(-1,0)$ & 0.43 & $1.296^{*}$ \\
$(+1,+30)$ & 0.43 & 0.629 \\
$(+1,+90)$ & -0.05 & 0.129 \\
$(+1,180)$ & -1.39 & -0.371 \\
$(+1,+250)$ & -2.52 & -0.871 \\
\hline
\end{tabular}

$*$ significant at the .10 level

$* *=$ significant at the .05 level

Table 11. "Under \$60 When Splitting” Company Sample- Fractional

\begin{tabular}{l|l|l}
\hline Days & Mean CAR (\%) & Generalized Sign Z \\
\hline$(-10,-2)$ & -0.18 & 0.561 \\
$(-1,0)$ & 0.58 & $1.405^{*}$ \\
$(+1,+30)$ & -1.41 & -1.127 \\
$(+1,+90)$ & -2.34 & $-1.548^{*}$ \\
$(+1,180)$ & -4.11 & -0.705 \\
$(+1,+250)$ & -7.78 & $1.338^{*}$ \\
\hline
\end{tabular}

$*=$ significant at the .10 level

Table 12. "Over $\$ 60$ When Splitting” Company Sample- Decimalized

$*$ significant at the .10 level

\begin{tabular}{l|l|l}
\hline Days & Mean CAR (\%) & Generalized Sign Z \\
\hline$(-10,-2)$ & 1.25 & $1.509^{*}$ \\
$(-1,0)$ & -0.33 & 0.906 \\
$(+1,+30)$ & 1.08 & 0.303 \\
$(+1,+90)$ & 3.49 & 0.303 \\
$(+1,180)$ & -0.71 & -0.300 \\
$(+1,+250)$ & -2.07 & 0.303 \\
\hline
\end{tabular}

Table 13. "Under $\$ 60$ When Splitting” Company Sample- Decimalized

\begin{tabular}{l|l|l}
\hline Days & Mean CAR (\%) & Generalized Sign Z \\
\hline$(-10,-2)$ & 1.75 & $1.637^{*}$ \\
$(-1,0)$ & 0.06 & 0.193 \\
$(+1,+30)$ & 1.92 & 1.156 \\
$(+1,+90)$ & 1.69 & $1.397^{*}$ \\
$(+1,180)$ & -0.07 & 0.193 \\
$(+1,+250)$ & 1.69 & -0.048 \\
\hline
\end{tabular}

$*$ = significant at the .10 level 
Table 14. Stock Sample- Overall Results (Decimalized and Fractional)

\begin{tabular}{l|l|l|l|l|l|l}
\hline & $\begin{array}{l}\text { Mean } \\
\text { CAR- 2:1 } \\
(\%)\end{array}$ & $\begin{array}{l}\text { Mean } \\
\text { CAR- 3:2 } \\
(\%)\end{array}$ & $\begin{array}{l}\text { Mean } \\
\text { CAR- 3:1 } \\
(\%)\end{array}$ & $\begin{array}{l}\text { Gen. Z- } \\
2: 1\end{array}$ & $\begin{array}{l}\text { Gen. Z- } \\
3: 2\end{array}$ & $\begin{array}{l}\text { Gen. Z- } \\
3: 1\end{array}$ \\
\hline$(-10,-2)$ & 1.00 & 0.24 & -0.07 & $2.006^{*}$ & 0.823 & -0.406 \\
$(-1,0)$ & 0.29 & 0.16 & 0.65 & 1.24 & 0.823 & -0.406 \\
$(+1,+30)$ & 1.43 & -1.41 & -1.32 & $1.432 *$ & -0.779 & -0.406 \\
$(+1,+90)$ & 1.05 & -0.47 & -6.60 & 0.474 & -0.378 & -0.406 \\
$(+1,180)$ & -0.27 & -1.34 & -14.81 & 0.665 & -1.179 & -1.162 \\
$(+1,+250)$ & -2.88 & 4.80 & -18.42 & -0.676 & 0.422 & $-1.918^{* *}$ \\
\hline
\end{tabular}

$*$ = significant at the .10 level

$* *=$ significant at the .05 level

Table 15. "2 for 1” Stock Split Sample- Fractional System/Large vs. Med. vs. Small Co

\begin{tabular}{|c|c|c|c|c|c|c|c|c|}
\hline Days & $\begin{array}{l}\text { Mean } \\
\text { CAR- } \\
\text { Over. (\%) }\end{array}$ & $\begin{array}{l}\text { Mean } \\
\text { CAR- } \\
\text { Large (\%) }\end{array}$ & $\begin{array}{l}\text { Mean } \\
\text { CAR- } \\
\text { Med. (\%) }\end{array}$ & $\begin{array}{l}\text { Mean } \\
\text { CAR- } \\
\text { Small } \\
(\%)\end{array}$ & $\begin{array}{l}\text { Gen. Z- } \\
\text { Over. }\end{array}$ & $\begin{array}{l}\text { Gen. Z- } \\
\text { Large }\end{array}$ & $\begin{array}{l}\text { Gen. Z- } \\
\text { Med. }\end{array}$ & $\begin{array}{l}\text { Gen. Z- } \\
\text { Small }\end{array}$ \\
\hline$(-10,-2)$ & -0.74 & -0.30 & -1.53 & -0.96 & 0.239 & 0.424 & -0.965 & 0.417 \\
\hline$(-1,0)$ & 0.59 & 0.82 & -0.09 & 0.96 & $1.349 *$ & $1.343^{*}$ & -0.465 & $1.388^{*}$ \\
\hline$(+1,+30)$ & 0.51 & -1.23 & 1.31 & 1.29 & 0.516 & 0.424 & -0.965 & $1.388^{*}$ \\
\hline$(+1,+90)$ & 0.14 & -1.25 & 2.46 & -0.59 & 0.239 & 0.883 & 0.535 & -1.040 \\
\hline$(+1,180)$ & 0.05 & -2.17 & 0.65 & 0.95 & 0.794 & 0.424 & 0.035 & 0.417 \\
\hline$(+1,+250)$ & -5.42 & -3.16 & -2.95 & -10.49 & -0.039 & 0.424 & 0.535 & -1.040 \\
\hline
\end{tabular}

$*$ = significant at the .10 level

Table 16. "2 for 1" Stock Split Sample- Decimalized System/Large vs. Med. vs. Small Co.

\begin{tabular}{|c|c|c|c|c|c|c|c|c|}
\hline Days & $\begin{array}{l}\text { Mean } \\
\text { CAR- } \\
\text { Over. (\%) }\end{array}$ & $\begin{array}{l}\text { Mean } \\
\text { CAR- } \\
\text { Large (\%) }\end{array}$ & $\begin{array}{l}\text { Mean } \\
\text { CAR- } \\
\text { Med. } \\
(\%)\end{array}$ & $\begin{array}{l}\text { Mean } \\
\text { CAR- } \\
\text { Small } \\
(\%)\end{array}$ & $\begin{array}{l}\text { Gen. Z- } \\
\text { Over. }\end{array}$ & $\begin{array}{l}\text { Gen. Z- } \\
\text { Large }\end{array}$ & $\begin{array}{l}\text { Gen. Z- } \\
\text { Med. }\end{array}$ & $\begin{array}{l}\text { Gen. Z- } \\
\text { Small }\end{array}$ \\
\hline$(-10,-2)$ & 2.60 & 2.20 & 2.52 & 3.06 & $2.546 * *$ & $1.943 * *$ & 0.868 & $1.628 *$ \\
\hline$(-1,0)$ & 0.02 & -0.03 & 0.34 & -0.28 & 0.427 & $1.472 *$ & 0.421 & -1.125 \\
\hline$(+1,+30)$ & 2.27 & 0.64 & 1.15 & 4.98 & $1.487 *$ & 0.057 & 0.868 & $1.628 *$ \\
\hline$(+1,+90)$ & 1.88 & -2.81 & 2.69 & 5.48 & 0.427 & $-1.829 * *$ & 0.868 & $1.628 *$ \\
\hline$(+1,180)$ & -0.56 & -1.94 & -3.87 & 4.24 & 0.162 & -0.886 & 0.421 & 0.711 \\
\hline$(+1,+250)$ & -0.57 & -2.89 & -7.12 & 8.53 & -0.898 & -0.414 & $-1.815^{* *}$ & 0.711 \\
\hline
\end{tabular}

$*=$ significant at the .10 level

$* *=$ significant at the .05 level

Table 17. "3 for 2” Stock Split Sample- Fractional System/Large vs. Med. vs. Small Co

\begin{tabular}{|c|c|c|c|c|c|c|c|c|}
\hline Days & $\begin{array}{l}\text { Mean } \\
\text { CAR- } \\
\text { Over. (\%) }\end{array}$ & $\begin{array}{l}\text { Mean } \\
\text { CAR- } \\
\text { Large (\%) }\end{array}$ & $\begin{array}{l}\text { Mean } \\
\text { CAR- } \\
\text { Med. (\%) }\end{array}$ & $\begin{array}{l}\text { Mean } \\
\text { CAR- } \\
\text { Small } \\
(\%)\end{array}$ & $\begin{array}{l}\text { Gen. Z- } \\
\text { Over. }\end{array}$ & $\begin{array}{l}\text { Gen. Z- } \\
\text { Large }\end{array}$ & $\begin{array}{l}\text { Gen. Z- } \\
\text { Med. }\end{array}$ & $\begin{array}{l}\text { Gen. Z- } \\
\text { Small }\end{array}$ \\
\hline$(-10,-2)$ & 1.36 & 0.70 & -0.68 & 3.66 & $1.343 *$ & 0.641 & 0.118 & $1.501 *$ \\
\hline$(-1,0)$ & 1.23 & 1.02 & 1.91 & 0.89 & $1.343 *$ & 0.641 & 1.120 & 0.605 \\
\hline$(+1,+30)$ & -2.75 & -2.99 & -9.24 & 2.67 & -0.801 & 0.641 & $-1.886^{* *}$ & -0.292 \\
\hline$(+1,+90)$ & -2.18 & -11.97 & 0.15 & 5.75 & -1.873 & -1.155 & -0.884 & 1.189 \\
\hline$(+1,180)$ & -2.66 & -20.60 & 0.01 & 13.14 & -1.337 & $-2.052 * *$ & 0.118 & -0.292 \\
\hline$(+1,+250)$ & 2.63 & -3.70 & 13.83 & 27.13 & -0.801 & -0.257 & -0.884 & -0.292 \\
\hline
\end{tabular}

$*$ = significant at the .10 level

$* *=$ significant at the .05 level 
Table 18. "3 for 2" Stock Split Sample- Decimalized System/Large vs. Med. vs. Small Co.

\begin{tabular}{l|l|l|l|l|l|l|l|l}
\hline & $\begin{array}{l}\text { Mean } \\
\text { CAR- } \\
\text { Over. (\%) }\end{array}$ & $\begin{array}{l}\text { Mean } \\
\text { CAR- } \\
\text { Large (\%) }\end{array}$ & $\begin{array}{l}\text { Mean } \\
\text { CAR- } \\
\text { Med. }(\%)\end{array}$ & $\begin{array}{l}\text { Mean } \\
\text { CAR- } \\
\text { Small } \\
(\%)\end{array}$ & $\begin{array}{l}\text { Gen. Z- } \\
\text { Over. }\end{array}$ & $\begin{array}{l}\text { Gen. Z- } \\
\text { Large }\end{array}$ & $\begin{array}{l}\text { Gen. Z- } \\
\text { Med. }\end{array}$ & $\begin{array}{l}\text { Gen. } \\
\text { Small }\end{array}$ \\
\hline$(-10,-2)$ & -1.20 & -1.14 & -2.93 & 0.05 & -0.272 & 0.012 & 0.575 & -0.961 \\
$(-1,0)$ & -1.21 & 0.09 & -2.11 & -1.83 & -0.272 & 1.012 & -0.580 & -0.961 \\
$(+1,+30)$ & 0.30 & -6.65 & 6.74 & 2.43 & -0.272 & -0.998 & 0.575 & 0.039 \\
$(+1,+90)$ & 1.72 & -0.76 & 3.07 & 3.19 & 1.537 & 1.012 & 0.575 & 1.039 \\
$(+1,180)$ & 0.34 & -14.95 & 14.99 & 4.63 & -0.272 & -0.998 & 0.575 & 0.039 \\
$(+1,+250)$ & 7.57 & -6.69 & 18.29 & 13.78 & 1.537 & -0.998 & $1.730^{* *}$ & $2.040^{* *}$ \\
\hline
\end{tabular}

$*=$ significant at the .10 level

$* *=$ significant at the .05 level 